\title{
PHOTOBIOLOGICAL SAFETY OF THE RECENTLY INTRODUCED ENERGY EFFICIENT HOUSEHOLD LAMPS
}

PÉTER PÁL NECZ and JÓZSEF BAKOS

National "Frédéric Joliot-Curie" Research Institute for Radiobiology and Radiohygiene, Budapest, Hungary

Department of Non-ionizing Radiations

\begin{abstract}
Objectives: Nowadays more and more newly introduced light sources (tungsten-halogen, compact fluorescent (CFL) and light-emitting diode (LED) lamps) are used in households. It is important to know whether their radiation poses any possible risk for human health or not. These light sources emit optical radiation not solely in the visible spectrum. Other bands emitted by these sources, i.e., ultraviolet and infrared, are potentially hazardous for human health. The visible light, especially the blue light, could also damage human retina. The purpose of this study was to determine the ultraviolet (UV) and blue light (BL) emissions from halogen bulbs, CFLs and LED lamps, and to evaluate them from the point of view of possible health risks for general public. Material and Methods: The exposure of UV and BL emissions from 19 types of CFLs, 11 types of halogen lamps and 4 types of LED lamps produced by different manufacturers were measured at $200 \mathrm{~mm}$ distance from the source. Results: The exposures to UV and BL were below the International Commission on Non-Ionizing Radiation Protection (ICNIRP) exposure limits in spite of the very conservative assumption of the assessment. Conclusions: Results of this study indicate that the UV and BL radiation from the newly introduced lamps does not exceed the current exposure limit values and thus, in comparison with the former incandescent bulbs, does not result in a higher risk for general public.
\end{abstract}

Key words:

Ultraviolet, Visible light, Blue light, Optical radiation, Hazard

\section{INTRODUCTION}

In the past century conventional incandescent bulb was almost the only source of electric light used in households. Due to energy saving policy [1] conventional incandescent bulbs (and other inefficient lighting methods) had to be phased out until September 2012. Consumers had to replace them with energy efficient light sources such as halogen bulbs, compact fluorescent lamps (CFLs) or light-emitting diode (LED) lamps. Since currently, these light sources are used in the majority of households it is important to know whether their optical radiation can pose any risk to human health or not.

These sources of light emit mainly optical radiation but not solely in the visible spectrum (VIS). There are some other ranges of non-ionizing radiation that are emitted by these sources and that are possibly hazardous for human health, such as: ultraviolet (UV), infrared (IR) radiation and intermediate frequency electromagnetic fields [2]. Also visible light, especially blue light (BL), can impair eyesight.

Received: February 20, 2014. Accepted: June 5, 2014

Corresponding author: P.P. Necz, National "Frédéric Joliot-Curie" Research Institute for Radiobiology and Radiohygiene, Department of Non-ionizing Radiations, Anna utca 5, Budapest, H-1775, Hungary (e-mail: necz.peter@osski.hu). 
The health effects of UV and BL radiation have been studied for decades. Besides beneficial effects of UV radiation (generation of vitamin $\mathrm{D}$ ), overexposure to it can cause acute (e.g., erythema, photokeratitis) and chronic (e.g., skin aging, melanoma and nonmelanoma skin cancer, cortical cataract) skin and ocular diseases [3,4]. In addition, "exposure to UVR contributes to immunosuppression, which is increasingly recognized as important in the development of skin cancer" [4].

Exposure to BL (300-700 nm with a $438 \mathrm{~nm}$ peak) could damage retina causing photoretinitis ("blue-light hazard") [5]. The age-related macula degeneration (AMD) can also be induced by exposure to BL and near UV light, especially in the case of aphakic eye [6,7].

In past decades, there were several studies carried out to determine the UV radiation from lamps used for residential lighting (e.g., incandescent bulbs, halogen and fluorescent lamps) [8-11]. The results show that these sources of light emit various levels of UV radiation but the values are significantly lower than the natural UV irradiance coming from the sun. Generally, the emitted UV levels from lamps are considered not to be dangerous for healthy persons [12]. Bloom et al. have stated that halogen lamps have UV-C and UV-B emissions which could harm human skin [13]. Early studies about UV radiation from CFLs had different results. Khazova and O'Hagan [14] have concluded that the UV emission from single-enveloped CFLs may cause overexposure of the skin by desk use. Klein et al. have examined 19 different compact fluorescent light bulbs, and they have found that despite the low UV irradiance the long time use can lead to a significant cumulative damage in the case of photosensitive people, such as lupus erythematosus [12,15]. There are few reports about the blue-light hazard of artificial light sources. Behar-Cohen et al. have assessed LED sources and concluded that the cold-white and warm-white LEDs are also in the "low-risk" group at $200 \mathrm{~mm}$ distance (the maximum permissible exposure time is 100-1300 s) [16]. Okuno et al. [17] have measured various light sources, e.g., welding arc lights, incandescent, halogen, LED, fluorescent and arc lamps, with a conclusion that the lamps used in households have low effective radiance and mean no hazard (at least in the case of short exposure time).

Development of manufacturing and spreading new light sources require drawing attention to these questions. The purpose of this study was to determine the UV and $\mathrm{BL}$ emissions from halogen bulbs, CFLs and LED lamps, respectively in order to evaluate the possible health risks they pose to general public.

\section{MATERIAL AND METHODS}

Ultraviolet and BL emissions from 19 types of CFLs, 11 types of halogen lamps and 4 types of LED lamps of different manufacturers were measured according to the IEC 62471:2006 standard [18]. Distribution of the investigated lamp types is shown in Table 1.

The measurement distance was set at $200 \mathrm{~mm}$, which is the minimum distance permitted by the standard to simulate the worst case situation during the use of lamps. Spectral irradiance of the lamps was measured by an IL783A spectroradiometer (International Light Technologies, Peabody, USA) in the 250-400 nm (UV) wavelength and by an ILT-900C spectroradiometer (International Light Technologies, Peabody, USA) in the 300-700 nm (BL) wavelength range. Both of them had a cosine corrected input optics with fused silica diffuser dome. In the case of BL measurements the instrument was set at 0.1 radian by the appropriate masking of the source. In addition, a $20 \mathrm{~mm}$ circle shaped hole was placed in front of the lamp and the irradiance was measured at $200 \mathrm{~mm}$ distance from the hole. The measurement uncertainties were $20 \%$ and $18 \%$ for UV and BL, respectively. Both instruments have a stray light better than $0.1 \%$. 
Table 1. Distribution of the investigated lamps specified by construction, color temperature and transparency

\begin{tabular}{lcccccc}
\hline \multirow{2}{*}{ Lamp type } & \multicolumn{3}{c}{$\begin{array}{c}\text { Construction } \\
(\mathrm{n})\end{array}$} & \multicolumn{2}{c}{$\begin{array}{c}\text { Transparency } \\
(\mathrm{n})\end{array}$} & \multirow{2}{*}{$\begin{array}{c}\text { Total } \\
\text { (n) }\end{array}$} \\
\cline { 2 - 6 } & linear & helical & bulb $^{\mathrm{a}}$ & transparent & frosted & \\
\hline CFL & 11 & 6 & 2 & 0 & 19 & 19 \\
Halogen & 0 & 0 & 11 & 11 & 0 & 11 \\
LED & 0 & 0 & 4 & 2 & 2 & 4 \\
\hline
\end{tabular}

CFL - compact fluorescent; LED-light-emitting diode.

${ }^{a}$ The bulb shape means a double-covered lamp with a bulb-shaped housing.

After measuring spectral irradiance, the biologically effective values were calculated according to the standard [17]. To assess the possible health risk of the exposure caused by the investigated lamps, actinic UV, near-UV and BL were determined and compared to the relevant exposure limit values (ELV).

\section{Applied exposure limit values}

Exposure limits of the International Commission on Non-Ionizing Radiation Protection (ICNIRP) [19,20] were used for the evaluation of safety of the lamps. These exposure limit values are equal to the exposure limits of exempt group of IEC 62471:2006 standard. Lamps that classified into this exempt group do not pose any photobiological hazard for unprotected skin and eye.

The ELV for actinic UV hazard radiant exposure is

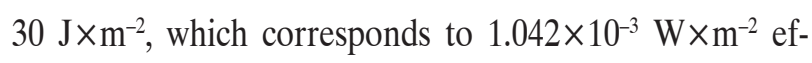
fective integrated irradiance for 8 -h period.

The ELV for near-UV radiant exposure is $10000 \mathrm{~J} \times \mathrm{m}^{-2}$, the irradiance of which is $3.47 \times 10^{-1} \mathrm{~W} \times \mathrm{m}^{-2}$ for 8 -h period. The ELV for blue light hazard weighted radiance is $100 \mathrm{~W} \times \mathrm{m}^{-2} \times \mathrm{sr}^{-1}$ for a $\mathrm{t}>10^{4} \mathrm{~s}$ period.

\section{Applied formulas}

For the assessment of actinic UV hazard, the effective ultraviolet irradiance $\left(\mathrm{E}_{\mathrm{S}}\right)$ was calculated using the following formula:

$$
\mathrm{E}_{\mathrm{S}}=\sum_{200}^{400} \mathrm{E}_{\lambda}(\lambda) \times \mathrm{S}_{\mathrm{UV}}(\lambda) \times \Delta \lambda
$$

where:

$\mathrm{E}_{\mathrm{S}}$ - effective ultraviolet irradiance $\left(\mathrm{W} \times \mathrm{m}^{-2}\right)$,

$\mathrm{E}_{\lambda}(\lambda)$ - spectral irradiance $\left(\mathrm{W} \times \mathrm{m}^{-2} \times \mathrm{nm}^{-1}\right)$,

$\mathrm{S}_{\mathrm{UV}}$ - actinic UV hazard weighting function,

$\Delta \lambda$ - bandwidth (nm).

The near-UV hazard the UV-A irradiance $\left(\mathrm{E}_{\mathrm{UV}-\mathrm{A}}\right)$ was calculated using the following formula:

$$
\mathrm{E}_{\mathrm{UV}-\mathrm{A}}=\sum_{315}^{400} \mathrm{E}_{\lambda}(\lambda) \times \Delta \lambda
$$

where:

$\mathrm{E}_{\mathrm{UV}-\mathrm{A}}-\mathrm{UV}$-A irradiance $\left(\mathrm{W} \times \mathrm{m}^{-2}\right)$,

$\mathrm{E}_{\lambda}(\lambda)$ - spectral irradiance $\left(\mathrm{W} \times \mathrm{m}^{-2} \times \mathrm{nm}^{-1}\right)$,

$\Delta \lambda$ - bandwidth (nm).

The retinal BL hazard weighted radiance was calculated by the use of this formula:

$$
\mathrm{L}_{\mathrm{B}}=\sum_{300}^{700} \mathrm{~L}_{\lambda}(\lambda) \times \mathrm{B}(\lambda) \times \Delta \lambda
$$

where:

$\mathrm{L}_{B}$ - blue-light hazard weighted radiance,

$\mathrm{L}_{\lambda}(\lambda)$ - spectral radiance $\left(\mathrm{W} \times \mathrm{m}^{-2} \times \mathrm{sr}^{-1} \times \mathrm{nm}^{-1}\right)$,

$\mathrm{B}(\lambda)$ - blue-light hazard weighting function,

$\Delta \lambda$ - bandwidth (nm). 


\section{RESULTS AND DISCUSSION}

The biologically effective UV and BL radiation from the investigated lamps was calculated and compared to the relevant exposure limit values.

Generally, the measured UV and BL values were below the exposure limit values of exempt group. It was so, even in spite of the very conservative assumption of exposure distance $(200 \mathrm{~mm})$ and exposure duration (8 h continuously), which are very unlikely during the intended normal use of these lamps. Technical specification and the calculated biologically effective $\mathrm{UV}$ and $\mathrm{BL}$ radiation from the investigated lamps are summarized in Table 2.

\section{Ultraviolet}

Correlations between power consumption and the effective UV irradiation also deserved examination. Since the CFLs consume less power to achieve the same luminous flux (energy per unit time $(\mathrm{dQ} / \mathrm{dt})$ that is radiated from a source over visible wavelengths) than the other light sources, it is more worthwhile to assess the relationship between the luminous flux ('brightness') and the measured UV levels.

The CFLs commonly have actinic UV radiation 4 times higher than the halogen bulbs of the same 'brightness' (Figure 1). The average luminous flux and actinic UV level of LED lamps are notably lower than those of the other sources due to different emission spectrum and lower energy consumption. The calculated effective UV radiation is below the ELV in every case, therefore, it is safe for healthy people provided the lamps are used properly.

The near-UV hazard of measured CFLs, halogen and LED lamps is also acceptable for compliance. Similarly to the full UV range, there is also a difference between the near-UV emissions from different types of the lamps. The UV level of CFLs is higher than that of halogen or LED lamps. These exposure levels are safe for healthy people. However, in the case of certain illnesses

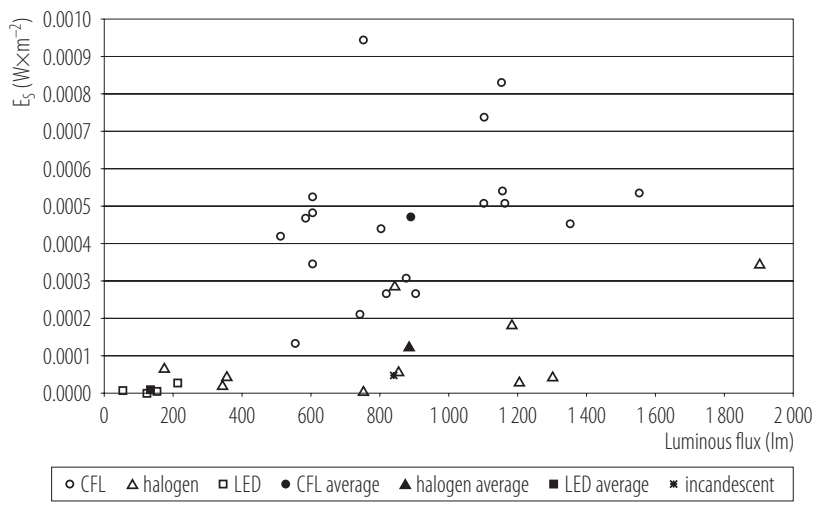

The empty symbols show each measurement, the filled symbols show the average values.

On average, the CFLs have about 5 times higher UV emissions than the halogen lamps at resembling luminous flux. Abbreviations as in Table 1.

Fig. 1. The relationship between the luminous flux and the effective ultraviolet $(\mathrm{UV})$ irradiance $\left(\mathrm{E}_{\mathrm{S}}\right)$ of the investigated lamps

(e.g., lupus erythematosus) despite the low emission level, it is important to consider exposure duration [12].

Another question is whether emission levels are influenced by the construction of the lamps or not. All of the investigated halogen lamps were double-enveloped (the inner quartz glass is covered by a bulb-shaped glass housing) which reduces emissions in the entire UV range. Due to this coating, the emission spectrum of these lamps is similar to the former incandescent bulbs. However, halogen bulbs without this layer cause much higher exposure, as has been found by Bloom et al. [13]. Therefore, using a double-layered halogen bulb is worth considering. In our study, the investigated compact fluorescent lamps had 3 different constructions: linear, helical and doublecoated ('bulb'). The results showed that the UV-A irradiance is also influenced by their construction: the average UV-A emissions from the double-coated CFLs are significantly lower than the emissions from the linear and helical models (Figure 2).

Former studies concerning UV radiation from household light sources have similar results - namely the UV level 
Table 2. The actinic $\mathrm{UV}\left(\mathrm{E}_{\mathrm{S}}\right)$, near-UV $\left(\mathrm{E}_{\mathrm{UV}-\mathrm{A}}\right)$ and $\mathrm{BL}\left(\mathrm{L}_{\mathrm{B}}\right)$ emissions from the investigated lamps*

\begin{tabular}{|c|c|c|c|c|c|c|}
\hline No. & Type & Construction & $\begin{array}{c}\text { Power } \\
(\mathrm{W})\end{array}$ & $\begin{array}{c}\mathrm{E}_{\mathrm{S}} \\
\left(\mathrm{W} \times \mathrm{m}^{-2}\right) \\
\end{array}$ & $\begin{array}{c}\mathrm{E}_{\mathrm{UV}-\mathrm{A}} \\
\left(\mathrm{W} \times \mathrm{m}^{-2}\right)\end{array}$ & $\begin{array}{c}\mathrm{L}_{\mathrm{B}} \\
\left(\mathrm{W} \times \mathrm{m}^{-2} \times \mathrm{sr}^{-1}\right)\end{array}$ \\
\hline 1 & CFL & linear & 11 & $4.85 \times 10^{-4}$ & $9.09 \times 10^{-2}$ & $7.11 \times 10^{0}$ \\
\hline 2 & CFL & linear & 11 & $4.23 \times 10^{-4}$ & $6.63 \times 10^{-2}$ & $7.87 \times 10^{0}$ \\
\hline 3 & CFL & linear & 11 & $3.51 \times 10^{-4}$ & $7.02 \times 10^{-2}$ & $1.44 \times 10^{1}$ \\
\hline 4 & CFL & linear & 11 & $5.29 \times 10^{-4}$ & $7.02 \times 10^{-2}$ & $1.51 \times 10^{1}$ \\
\hline 5 & CFL & linear & 14 & $4.43 \times 10^{-4}$ & $1.00 \times 10^{-1}$ & $1.13 \times 10^{1}$ \\
\hline 6 & CFL & linear & 14 & $2.16 \times 10^{-4}$ & $1.02 \times 10^{-1}$ & $9.25 \times 10^{0}$ \\
\hline 7 & CFL & linear & 15 & $3.09 \times 10^{-4}$ & $8.55 \times 10^{-2}$ & $1.25 \times 10^{1}$ \\
\hline 8 & CFL & linear & 15 & $9.47 \times 10^{-4}$ & $1.38 \times 10^{-1}$ & $1.01 \times 10^{1}$ \\
\hline 9 & CFL & linear & 18 & $5.10 \times 10^{-4}$ & $1.15 \times 10^{-1}$ & $1.30 \times 10^{1}$ \\
\hline 10 & CFL & linear & 20 & $8.35 \times 10^{-4}$ & $1.79 \times 10^{-1}$ & $1.25 \times 10^{1}$ \\
\hline 11 & CFL & linear & 20 & $7.40 \times 10^{-4}$ & $1.56 \times 10^{-1}$ & $1.18 \times 10^{1}$ \\
\hline 12 & CFL & bulb $^{\mathrm{a}}$ & 16 & $2.71 \times 10^{-4}$ & $2.09 \times 10^{-2}$ & $9.56 \times 10^{0}$ \\
\hline 13 & CFL & bulb & 20 & $5.13 \times 10^{-4}$ & $4.49 \times 10^{-2}$ & $1.36 \times 10^{1}$ \\
\hline 14 & CFL & helical & 11 & $4.70 \times 10^{-4}$ & $5.62 \times 10^{-2}$ & $9.52 \times 10^{0}$ \\
\hline 15 & CFL & helical & 11 & $1.38 \times 10^{-4}$ & $8.46 \times 10^{-2}$ & $9.88 \times 10^{0}$ \\
\hline 16 & CFL & helical & 15 & $2.71 \times 10^{-4}$ & $1.17 \times 10^{-1}$ & $1.14 \times 10^{1}$ \\
\hline 17 & CFL & helical & 20 & $5.44 \times 10^{-4}$ & $1.06 \times 10^{-1}$ & $1.03 \times 10^{1}$ \\
\hline 18 & CFL & helical & 20 & $4.57 \times 10^{-4}$ & $9.46 \times 10^{-2}$ & $1.14 \times 10^{1}$ \\
\hline 19 & CFL & helical & 23 & $5.38 \times 10^{-4}$ & $1.28 \times 10^{-1}$ & $1.52 \times 10^{1}$ \\
\hline 20 & halogen & bulb & 18 & $7.00 \times 10^{-5}$ & $4.32 \times 10^{-3}$ & $7.32 \times 10^{0}$ \\
\hline 21 & halogen & bulb & 28 & $2.40 \times 10^{-5}$ & $9.33 \times 10^{-3}$ & $1.49 \times 10^{1}$ \\
\hline 22 & halogen & bulb & 28 & $4.90 \times 10^{-5}$ & $2.07 \times 10^{-2}$ & $1.79 \times 10^{1}$ \\
\hline 23 & halogen & bulb & 52 & $6.00 \times 10^{-6}$ & $3.25 \times 10^{-2}$ & $4.86 \times 10^{1}$ \\
\hline 24 & halogen & bulb & 52 & $2.74 \times 10^{-4}$ & $5.80 \times 10^{-2}$ & $4.31 \times 10^{1}$ \\
\hline 25 & halogen & bulb & 53 & $2.90 \times 10^{-4}$ & $3.17 \times 10^{-2}$ & $4.27 \times 10^{1}$ \\
\hline 26 & halogen & bulb & 53 & $6.10 \times 10^{-5}$ & $5.21 \times 10^{-2}$ & $3.66 \times 10^{1}$ \\
\hline 27 & halogen & bulb & 70 & $6.07 \times 10^{-4}$ & $4.49 \times 10^{-2}$ & $6.88 \times 10^{1}$ \\
\hline 28 & halogen & bulb & 70 & $4.75 \times 10^{-5}$ & $3.38 \times 10^{-2}$ & $6.39 \times 10^{1}$ \\
\hline 29 & halogen & bulb & 70 & $1.86 \times 10^{-4}$ & $6.22 \times 10^{-2}$ & $4.93 \times 10^{1}$ \\
\hline 30 & halogen & bulb & 105 & $3.48 \times 10^{-4}$ & $1.89 \times 10^{-2}$ & $9.16 \times 10^{1}$ \\
\hline 31 & LED & bulb & 2 & $7.00 \times 10^{-6}$ & $5.00 \times 10^{-5}$ & $1.21 \times 10^{1}$ \\
\hline 32 & LED & bulb & 2 & $3.00 \times 10^{-6}$ & $2.00 \times 10^{-5}$ & $4.97 \times 10^{0}$ \\
\hline 33 & LED & bulb & 2 & $6.00 \times 10^{-6}$ & $1.90 \times 10^{-5}$ & $1.00 \times 10^{0}$ \\
\hline 34 & LED & bulb & 5 & $2.90 \times 10^{-5}$ & $1.09 \times 10^{-4}$ & $3.59 \times 10^{0}$ \\
\hline 35 & incandescent & bulb & 60 & $5.00 \times 10^{-5}$ & $3.22 \times 10^{-2}$ & $2.57 \times 10^{0}$ \\
\hline
\end{tabular}

UV - ultraviolet; BL - blue light.

* Every measured and calculated value is below the relevant ELV.

a The 'bulb' construction means a double-covered lamp with a bulb-shaped housing except the incandescent lamp.

Other abbreviations as in Table 1. 


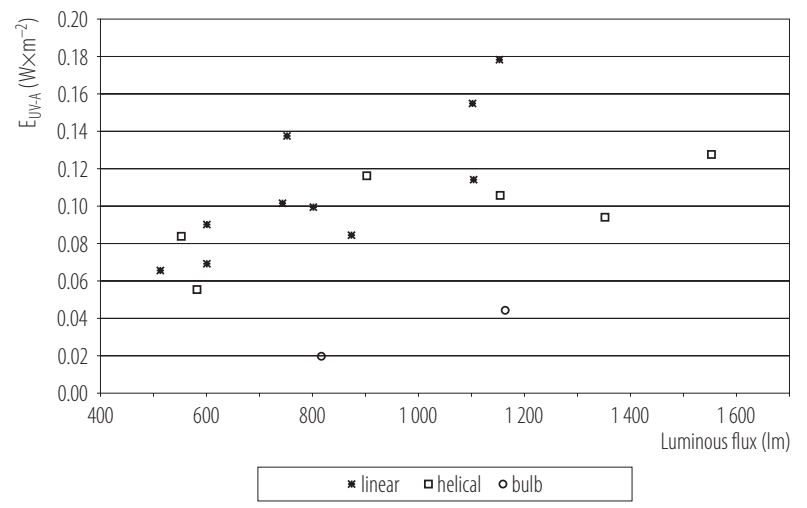

Fig. 2. The dependence of the ultraviolet A (UV-A) irradiance $\left(\mathrm{E}_{\mathrm{UV}-\mathrm{A}}\right)$ of the investigated compact fluorescent lamps by design and construction

of CFLs does not exceed the limit values, but at some wavelengths (especially in the UV-C range) it is higher than the UV level of the sunlight and therefore, it can lead to a cumulative damage to human health $[9,21]$.

\section{Blue-light}

The calculated values of BL hazard radiance over all the investigated lamps were also under the exposure limit values. The relationship between the luminous flux and the level of BL radiation was also analyzed (Figure 3). The BL levels of CFLs and LEDs were nearly constant, with only a minimal rising noticeable at high luminous flux. This phenomenon is caused by the emission spectrum since

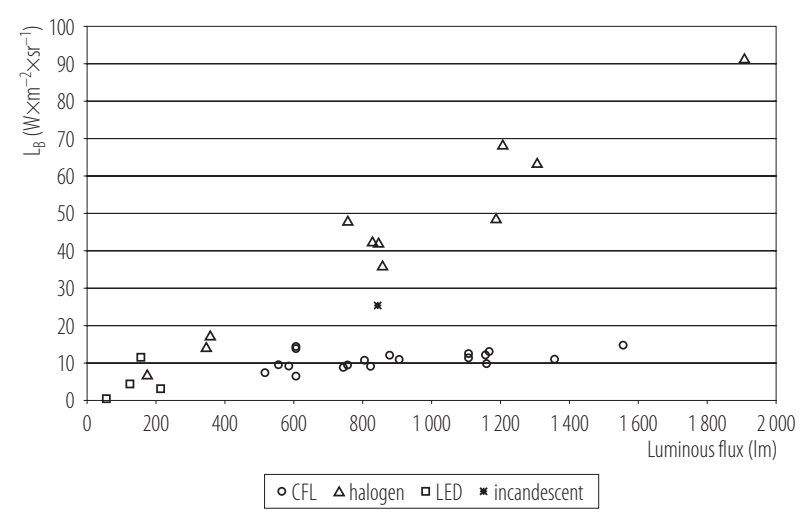

Abbreviations as in Table 1.

Fig. 3. The blue-light radiance $\left(\mathrm{L}_{\mathrm{B}}\right)$ of the investigated lamps these lamps have low relative emission at the peak wavelength of the BL hazard weighting function $(438 \mathrm{~nm})$. Due to this, low emission level of BL hazard radiance reaches approximately $1 / 10$ of the ELV. On the contrary, the BL radiance of halogen lamps is increasing linearly along with the luminous flux. There are few publications reporting about the BL radiation of residential lighting. Okuno et al. [17] have measured resembling BL values for fluorescent lamps.

\section{CONCLUSIONS}

The results of this study indicate that the UV and BL radiation of the newly introduced lamps does not exceed the current exposure limit values and thus, in comparison with the former incandescent bulbs, does not cause a higher risk for general public. Despite the low UV and $\mathrm{BL}$ radiation, in sensitive subjects an increased risk of detrimental skin and eye reactions may occur due to the illness or medications used. In addition, the halogen bulbs with equivalent luminous flux have lower actinic UV emission than CFLs. Therefore, these lamps are safer for the purpose of desk lighting. It is difficult to compare our results with the formerly published studies since measurements were not made at a standardized distance from the sources. The distances lower than $200 \mathrm{~mm}$ are irrelevant for general household use. The measurements must be carried out according to the requested minimal distances specified by the international standards.

The rapid development and introduction of new types of lamps require continuous monitoring of their hazards and assessment of the risks they pose in the future.

\section{ACKNOWLEDGMENTS}

Authors are grateful to Dr. György Thuróczy (National "Frédéric Joliot-Curie" Research Institute for Radiobiology and Radiohygiene, Budapest, Hungary) for the help with the manuscript. 


\section{REFERENCES}

1. Commission regulation (EC) No. 244/2009 of 18 March 2009 on implementing directive 2005/32/EC of the European Parliament and of the Council with regard to ecodesign requirements for non-directional household lamps. Off J Eur Union. 2009;L(76):3-16.

2. Bakos J, Nagy N, Juhasz P, Thuroczy G. Spot measurements of intermediate frequency electric fields in the vicinity of compact fluorescent lamps. Radiat Protect Dosimetry. 2010;142(2-4):354-7, http://dx.doi.org/10.1093/rpd/ncq276.

3. National Radiological Protection Board. Health effects from ultraviolet radiation - Report of an advisory group on nonionizing radiation. Documents of the NRPB. 2002;13.

4. Balk SJ. Technical report - ultraviolet radiation: A hazard to children and adolescents. Pediatrics. 2011;127(3):E791-817, http://dx.doi.org/10.1542/peds.2010-3502.

5. Cesarini JP. [Blue light hazards for ocular lesions]. Radioprotection. 2009;44(4):463-78. French, http://dx.doi. org/10.1051/radiopro/2009016.

6. Algvere PV, Marshall J, Seregard S. Age-related maculopathy and the impact of blue light hazard. Acta Ophthalmol Scan. 2006;84(1):4-15, http://dx.doi.org/10.1111/j.1600-04 20.2005.00627.x.

7. Taylor HR, West S, Munoz B, Rosenthal FS, Bressler SB, Bressler NM. The long-term effects of visible-light on the eye. Arch Ophthalmol. 1992;110(1):99-104, http://dx.doi. org/10.1001/archopht.1992.01080130101035.

8. Cole C, Forbes PD, Davies RE, Urbach F. Effect of indoor lighting on normal skin. Ann N Acad Sci. 1985 Sep 20;453: 305-16, http://dx.doi.org/10.1111/j.1749-6632.1985.tb11819.x.

9. Nuzum-Keim AD, Sontheimer RD. Ultraviolet light output of compact fluorescent lamps: Comparison to conventional incandescent and halogen residential lighting sources. Lupus. 2009;18(6):556-60, http://dx.doi. org/10.1177/0961203309103052.

10. Maxwell KJ, Elwood JM. UV-radiation from fluorescent lights. Lancet. 1983;2(8349):579, http://dx.doi.org/10.1016/ S0140-6736(83)90614-1.
11. Biella U. [UV radiation exposure caused by fluorescent lights]. Dermatologische Monatschrift. 1990;176(4):235-8. German.

12. Klein RS, Sayre RM, Dowdy JC, Werth VP. The risk of ultraviolet radiation exposure from indoor lamps in lupus erythematosus. Autoimmun Rev. 2009;8(4):320-4, http://dx.doi. org/10.1016/j.autrev.2008.10.003.

13. Bloom E, Cleaver J, Sayre RM, Maibach HI, Polansky JR. Halogen lamp phototoxicity. Dermatology. 1996;193(3): 207-11, http://dx.doi.org/10.1159/000246247.

14. Khazova M, O’Hagan JB. Optical radiation emissions from compact fluorescent lamps. Rad Prot Dosimetry. 2008;131(4):521-5, http://dx.doi.org/10.1093/rpd/ncn234.

15. Moseley H, Ferguson J. The risk to normal and photosensitive individuals from exposure to light from compact fluorescent lamps. Photodermatol Photo. 2011;27(3):131-7, http://dx.doi.org/10.1111/j.1600-0781.2011.00576.x.

16. Behar-Cohen F, Martinsons C, Vienot F, Zissis G, Barlier-Salsi A, Cesarini JP, et al. Light-emitting diodes (LED) for domestic lighting: Any risks for the eye? Prog Retin Eye Res. 2011; 30(4):239-57, http://dx.doi.org/10.1016/j.preteyeres.2011.04.002.

17. Okuno T, Saito H, Ojima J. Evaluation of blue-light hazards from various light sources. Developments in ophthalmology. 2002;35:104-12, http://dx.doi.org/10.1159/000060814.

18. International Electrotechnical Commission. IEC 62471: 2006. Photobiological safety of lamps and lamp systems. Geneva: IEC; 2006.

19. ICNIRP Guidelines on limits of exposure to broad-band incoherent optical radiation $(0.38$ to $3 \mathrm{~mm})$. Health Phys. 1997;73(3):539-54.

20. McKinlay AF, Bernhardt JH, Ahlbom A, Cesarini JP, de Gruijl FR, Hietanen M, et al. ICNIRP Guidelines on limits of exposure to ultraviolet radiation of wavelengths between $180 \mathrm{~nm}$ and $400 \mathrm{~nm}$ (incoherent optical radiation). Health Phys. 2004;87(2): 171-86, http://dx.doi.org/10.1097/00004032-200408000-00006.

21. Klein RS, Werth VP, Dowdy JC, Sayre RM. Analysis of compact fluorescent lights for use by patients with photosensitive conditions. Photochem Photobiol. 2009;85(4):1004-10, http://dx.doi.org/10.1111/j.1751-1097.2009.00540.x.

This work is available in Open Access model and licensed under a Creative Commons Attribution-NonCommercial 3.0 Poland License - http://creativecommons.org/ licenses/by-nc/3.0/pl/deed.en. 